\section{A Survey of Watermelon Germplasm for Inhibitory Seed Exudates}

\author{
Howard F. Harrison, Jr. ${ }^{1,4}$, Amnon Levi ${ }^{2}$, and C.S. Kousik ${ }^{3}$ \\ U.S. Department of Agriculture, Agriculture Research Service, U.S. \\ Vegetable Laboratory, 2700 Savannah Highway, Charleston, SC 29414
}

Additional index words. allelopathy, Citrullus lanatus v. lanatus, C. lanatus v. citroides, C. colocynthis, Phythophthora capsici, Panicum miliaceum

\begin{abstract}
Watermelon [Citrullus lanatus v. lanatus (Thunb.) Matsum \& Nakai] seed exudates are inhibitory to germination and seedling growth of other plant species. A miniature bioassay experiment that measured proso millet (Panicum miliaceum L.) radicle growth was used to assess the inhibition caused by seed exudates of 125 genotypes of watermelon and related Citrullus species. Exudates of most genotypes were not inhibitory; however, exudates of 53 accessions reduced radicle growth in comparison with the control. In subsequent proso millet radicle growth experiments, genotypes were found to vary in inhibitory potential, and concentration response curves generated using filtered, pasteurized exudates were different among genotypes. Filter-sterilized seed exudates of Citrullus accessions also varied in the level of inhibition in a bioassay that measured their effect on sporangia formation by the watermelon pathogen, Phytophthora capsici. These observations suggest that constituents in Citrullus seed exudates affect organisms in the spermosphere and that the inhibitory potential of seed exudates varies among genotypes. Differences in concentration response curves in the millet bioassay and differences in the relative inhibition of genotypes in the millet and fungus bioassays indicate that the inhibitory constituents in seed exudates vary among genotypes.
\end{abstract}

Allelopathy has traditionally been defined as the inhibitory effect of compounds released by one plant on another plant. A broader but less accepted definition of the term includes effects of plants on microorganisms that are mediated by biological chemicals (Rice, 1984). Allelopathy in the Cucurbitaceae was first reported by Putnam and Duke (1974) who screened the U.S. PI collection of cucumber (Cucumis sativus) germplasms and identified accessions with varying allelopathic potentials. Lockerman and Putnam $(1979,1981)$ subsequently demonstrated that suppression of proso millet (Panicum miliaceum) and white mustard (Brassica alba) by cucumber was largely the result of allelopathy and that allelopathic genotypes were competitive against weeds. $\mathrm{Yu}$ and Matsui (1994) found that cucumber root exudates contained a number of simple and complex phenolic compounds and organic acids that were inhibitory in a lettuce (Lactuca sativus) seedling growth bioassay. Soil sickness observed after repeated cropping with certain cucurbit crops was attributed to autotoxicity of compounds in root

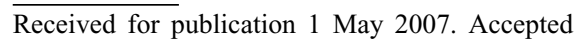
for publication 24 Aug. 2007.

Mention of a trademark name or proprietary product does not constitute a warranty or guarantee by the U.S. Department of Agriculture nor does it imply exclusion of other products that may also be suitable. ${ }^{1}$ Research agronomist.

${ }^{2}$ Research geneticist.

${ }^{3}$ Research plant pathologist.

${ }^{4}$ To whom reprint requests should be addressed; e-mail howard.harrison@ars.usda.gov
}

exudates and released by decomposing root tissues (Yu, 2001; Yu et al., 2000).

Germinating seeds release many compounds that affect organisms in the spermosphere. The role of seed exudates in stimulating the germination and growth of beneficial and harmful microorganisms has been extensively investigated, and this subject has been reviewed recently (Nelson, 1990, 2004). In some instances, constituents in seed exudates are inhibitory to microorganisms and protect the germinating seed against invasion by pathogens (Rose et al., 2006). Seed exudates may also be allelopathic against plants, and there are several reports of phytotoxic effects of seed exudates (Higashinakasu et al., 2004; Kushima et al., 1998; Ohno et al., 2001; Yamada et al., 1995). Kushima et al. (1998) reported that watermelon seed exudates were inhibitory to the root growth of several species in petri dish bioassays. They found that the exudates contained vanillic acid at a concentration that inhibited the growth of the test species in a bioassay. Otlewski et al. (1987) reported that watermelon seeds contained small peptides that function as protease inhibitors.

Phytophthora capsici is known to infect plants species in the families, cucurbitaceae, solanaceae, and leguminosae (Hausbeck and Lamour, 2004), and it causes an important disease in watermelon (Jester et al., 2006; Wiant, 1940). One objective of this research was to develop a miniature bioassay for inhibitory seed exudates and use it to assess the allelopathic potential of Citrullus germplasm. The effect of filter-sterilized seed exudates of Citrullus genotypes was also tested in a Phytophthora capsici bioassay that measured sporangia formation.
Proso millet radicle growth bioassay. The availability of seeds of most accessions was limited; thus, a bioassay that required few seeds was developed. Watermelon seeds were surface-sterilized by immersing in $70 \%$ ethanol for $2 \mathrm{~min}$, thoroughly rinsed with distilled water, and air-dried at room temperature. A Whatman \#1 (Whatman, Springfield, Kent, England) filter paper disk was placed in a $35-\mathrm{mm}$ plastic petri dish and $0.5 \mathrm{~mL}$ distilled water was added. One Citrullus seed was added to each dish for genotypes with seed weights $\geq 7.0 \mathrm{~g} \cdot 100^{-1}$ seeds, and two seeds per dish were added for genotypes with seed weights $<7.0 \mathrm{~g} \cdot 100^{-1}$ seeds. Ten proso millet seeds were subsequently added to each dish, and the seeds were incubated in the dark at $24^{\circ} \mathrm{C}$. After $72 \mathrm{~h}$, the petri dishes were placed in a freezer to stop growth. The dishes were thawed, millet radicle lengths were measured with an electronic caliper, and average radicle length was determined for each dish.

Preliminary germplasm evaluation. Germplasm evaluated in the preliminary study included eight accessions from the U.S. Plant Introduction (USPI) collection of Citrullus colocynthis (L) Schrad., nine USPI accessions from the Citrullus lanatus v. citroides (Bailey) Mansf. collection, and 108 watermelon USPI accessions, cultivars, and breeding lines. The experiment was arranged in a completely random design with three replications and was repeated three times. Data were combined, SE of the means were determined, and the $\mathrm{F}$ test at $P \leq 0.05$ was used to separate genotype means from the control. Linear regression analysis was used to determine if Citrullus seed weight (doubled for genotypes less than $7.0 \mathrm{~g} \cdot 100^{-1}$ seeds) was correlated to millet radicle length.

Retesting selected genotypes. Nine genotypes that varied in the initial screening experiment (Charleston Gray, PI 432337, PI 532738, 389-5-xx-15, 406-1-xx-7, 413-5-xx5, 416-1-xx-5-25, 416-4-xx-6, and 416-5-xx11) were retested using the bioassay procedure described previously. The experiment was arranged in a completely random design with five replicates and repeated four times. Data were combined and subjected to analysis of variance in a factorial design in which genotype was the first factor and experiment was the second factor. Genotype means were separated using Fisher's protected least significant difference (LSD) at $P \leq 0.05$.

Concentration response for seed exudates in the millet seedling radicle growth bioassay. Eight Citrullus genotypes (Charleston Gray, PI 167125, PI 432337, PI 482246, PI 500354, PI 532,738, 406-1-xx-7, and 413$5-\mathrm{xx}-7)$ were selected for this experiment based on activity in the previous study and seed availability. Seeds were soaked in distilled water $\left(30 \mathrm{~g}\right.$ seeds. $\left.60 \mathrm{~mL}^{-1}\right)$ on a wrist action shaker in the dark at $22^{\circ} \mathrm{C}$. After $24 \mathrm{~h}$, the seeds were strained out and discarded and the volume of the exudates was adjusted to $60 \mathrm{~mL}$. Exudates were filtered through Whatman \#1 filter paper and then through 1.2- $\mu \mathrm{m}$ 
Table 1. Response of proso millet radicle growth to Citrullus seed exudate in a petri dish bioassay.

\begin{tabular}{|c|c|c|c|c|c|c|c|c|c|}
\hline Genotype $^{z}$ & Species $^{\mathrm{y}}$ & $\begin{array}{c}\text { Seed wt } \\
\left(\mathrm{g} \cdot 100 \text { seeds }^{-1}\right)\end{array}$ & $\begin{array}{l}\text { Radicle length }^{\mathrm{x}} \\
(\mathrm{mm})\end{array}$ & SEM $^{\mathrm{w}}$ & Genotype $^{z}$ & Species $^{\mathrm{y}}$ & $\begin{array}{c}\text { Seed wt } \\
\left(\mathrm{g} \cdot 100 \text { seeds }^{-1}\right)\end{array}$ & $\begin{array}{l}\text { Radicle length } \\
(\mathrm{mm})\end{array}$ & SEM $^{\mathrm{w}}$ \\
\hline Control & - & - & 23.4 & 1.8 & PI 248178 & Cll & 11.3 & 20.1 & 7.2 \\
\hline PI 195297 & $\mathrm{Cc}$ & 6.1 & 22.3 & 4.4 & PI 249008 & Cll & 13.7 & $17.5^{*}$ & 5.2 \\
\hline PI 346082 & $\mathrm{Cc}$ & 3.3 & 26.6 & 4.4 & PI 249009 & Cll & 16.2 & 21.9 & 3.8 \\
\hline PI 386016 & $\mathrm{Cc}$ & 3.6 & 20.0 & 4.0 & PI 306364 & Cll & 5.4 & $15.4^{*}$ & 5.1 \\
\hline PI 386018 & $\mathrm{Cc}$ & 4.0 & 22.3 & 5.3 & PI 306366 & Cll & 8.3 & 19.4 & 4.4 \\
\hline PI 386024 & $\mathrm{Cc}$ & 4.2 & 22.5 & 2.9 & PI 306782 & Cll & 14.1 & 18.9 & 3.4 \\
\hline PI 386025 & $\mathrm{Cc}$ & 4.3 & 22.7 & 5.6 & PI 307608 & Cll & 9.5 & 24.3 & 8.7 \\
\hline PI 386026 & $\mathrm{Cc}$ & 4.4 & 23.9 & 5.1 & PI 307748 & Cll & 4.8 & $16.7 *$ & 5.3 \\
\hline PI 432337 & $\mathrm{Cc}$ & 4.2 & 27.0 & 3.4 & PI 307749 & Cll & 9.8 & 19.1 & 6.0 \\
\hline PI 244018 & Clc & 5.0 & 23.9 & 4.9 & PI 307750 & Cll & 7.3 & 21.7 & 5.9 \\
\hline PI 244019 & Clc & 4.4 & 21.8 & 4.0 & PI 346787 & Cll & 8.5 & 15.1 & 3.1 \\
\hline PI 255137 & Clc & 9.8 & 25.9 & 5.0 & PI 357676 & Cll & 8.9 & 27.7 & 4.2 \\
\hline PI 271779 & $\mathrm{Clc}$ & 11.4 & 22.6 & 5.1 & PI 379251 & Cll & 12.3 & 24.7 & 6.0 \\
\hline PI 299378 & $\mathrm{Clc}$ & 13.8 & 24.4 & 4.4 & PI 379256 & Cll & 12.0 & 20.7 & 6.1 \\
\hline PI 299379 & $\mathrm{Clc}$ & 15.6 & $16.6^{*}$ & 4.3 & PI 381713 & Cll & 11.8 & 20.1 & 4.2 \\
\hline PI 482246 & Clc & 20.2 & 23.8 & 5.2 & PI 381741 & Cll & 4.7 & $16.9^{*}$ & 4.0 \\
\hline PI 482252 & $\mathrm{Clc}$ & 12.0 & 21.8 & 6.0 & PI 385964 & Cll & 7.1 & 21.9 & 2.7 \\
\hline PI 500354 & Clc & 10.0 & 29.8 & 2.9 & PI 479704 & Cll & 10.2 & $32.6^{*}$ & 3.5 \\
\hline PI 532738 & $\mathrm{Clc}$ & 15.8 & 30.9 & 7.9 & PI 482246 & Cll & 8.9 & 26.7 & 7.4 \\
\hline Griffin 1729 & Cll & 4.4 & $16.5^{*}$ & 4.1 & PI 482256 & Cll & 17.7 & $14.7 *$ & 7.6 \\
\hline PI 105445 & Cll & 7.9 & 19.7 & 2.3 & PI 482279 & Cll & 12.9 & 22.6 & 4.2 \\
\hline PI 163204 & Cll & 9.7 & $17.2 *$ & 4.0 & PI 494527 & Cll & 14.1 & $11.7^{*}$ & 4.9 \\
\hline PI 163574 & Cll & 10.4 & $14.6^{*}$ & 5.5 & PI 494529 & Cll & 11.7 & $11.8 *$ & 3.9 \\
\hline PI 164146 & Cll & 6.9 & 20.6 & 3.1 & PI 494530 & Cll & 12.8 & 25.0 & 3.8 \\
\hline PI 164247 & Cll & 10.8 & 19.7 & 2.2 & PI 494531 & Cll & 14.6 & 19.6 & 7.0 \\
\hline PI 164543 & Cll & 10.5 & $15.8 *$ & 3.7 & PI 494816 & Cll & 9.4 & 20.4 & 4.4 \\
\hline PI 164570 & Cll & 9.3 & $15.7 *$ & 3.0 & PI 500354 & Cll & 10.0 & 29.8 & 2.9 \\
\hline PI 164633 & Cll & 8.7 & $16.1 *$ & 4.1 & PI 532810 & Cll & 7.4 & 18.8 & 4.0 \\
\hline PI 164634 & Cll & 9.1 & $17.7 *$ & 5.0 & PI 559992 & Cll & 14.0 & 19.8 & 4.6 \\
\hline PI 164636 & Cll & 9.6 & 18.8 & 4.9 & PI 599993 & Cll & 13.4 & 20.8 & 5.7 \\
\hline PI 164685 & Cll & 7.7 & $16.5^{*}$ & 3.2 & PI 559995 & Cll & 12.1 & $15.3 *$ & 7.4 \\
\hline PI 164977 & Cll & 5.9 & $13.5^{*}$ & 4.5 & PI 595203 & Cll & 10.2 & 20.7 & 4.2 \\
\hline PI 165002 & Cll & 9.4 & 19.0 & 6.4 & PI 596666 & Cll & 4.1 & 26.4 & 4.8 \\
\hline PI 165523 & Cll & 11.3 & 20.1 & 7.2 & $205-x x-33$ & Cll & 6.5 & 19.0 & 7.9 \\
\hline PI 167059 & Cll & 9.5 & $15.0 *$ & 6.0 & $210-341-31$ & Cll & 3.2 & 21.6 & 3.3 \\
\hline PI 167125 & Cll & 6.4 & $13.5^{*}$ & 6.1 & $385-3-x x-8$ & Cll & 2.9 & $14.3 *$ & 5.4 \\
\hline PI 167126 & Cll & 11.2 & $12.4 *$ & 4.6 & $385-3-x x-23$ & Cll & 4.0 & $14.9 *$ & 4.1 \\
\hline PI 167219 & Cll & 10.3 & $15.7 *$ & 7.8 & $389-5-x x-15$ & Cll & 3.1 & 19.5 & 4.8 \\
\hline PI 169232 & Cll & 9.9 & $17.9 *$ & 2.6 & $392-4-x x-9-28$ & Cll & 2.9 & $14.3^{*}$ & 5.4 \\
\hline PI 169245 & Cll & 13.4 & 21.0 & 10.9 & 398-xx & Cll & 9.3 & 18.3 & 3.4 \\
\hline PI 169253 & Cll & 6.0 & $17.8^{*}$ & 8.9 & $398-4-x x-4$ & Cll & 2.9 & 27.3 & 7.3 \\
\hline PI 169278 & Cll & 7.5 & 25.9 & 7.0 & $398-4-x x-3-24$ & Cll & 3.3 & $13.9^{*}$ & 4.4 \\
\hline PI 169292 & $\mathrm{Cll}$ & 8.8 & $14.0 *$ & 4.9 & $406-1-x x-6$ & Cll & 6.0 & 25.7 & 6.4 \\
\hline PI 169300 & Cll & 10.9 & 21.6 & 3.2 & 406-1-xx-7 & Cll & 5.2 & $14.7^{*}$ & 3.8 \\
\hline PI 171579 & Cll & 8.5 & 19.8 & 3.0 & $406-1-x x-10$ & Cll & 5.9 & $14.0^{*}$ & 3.7 \\
\hline PI 171585 & Cll & 11.9 & 21.5 & 4.2 & 413-1-xx-17 & Cll & 5.4 & $14.9^{*}$ & 4.0 \\
\hline PI 172786 & Cll & 12.8 & 22.6 & 3.0 & $413-5-x x-5$ & Cll & 5.2 & $16.1^{*}$ & 2.5 \\
\hline PI 172787 & Cll & 8.6 & $15.0 *$ & 3.4 & $413-5-x x-17$ & Cll & 5.4 & $14.9 *$ & 4.0 \\
\hline PI 172788 & Cll & 11.7 & 21.2 & 3.4 & $413-5-x x-19$ & Cll & 6.3 & $12.9 *$ & 4.9 \\
\hline PI 174106 & Cll & 8.6 & 18.8 & 6.2 & $413-5-x x-32$ & Cll & 3.6 & $13.0^{*}$ & 3.6 \\
\hline PI 175653 & Cll & 10.4 & $13.9^{*}$ & 4.6 & $413-5-x x-7-27$ & Cll & 4.3 & 19.5 & 6.4 \\
\hline PI 175655 & Cll & 8.0 & $16.6^{*}$ & 3.2 & $413-41-x x-13$ & Cll & 5.1 & $15.5^{*}$ & 4.7 \\
\hline PI 175657 & Cll & 9.7 & $13.9^{*}$ & 4.4 & 416-x-1-xx & Cll & 8.7 & $13.9^{*}$ & 3.7 \\
\hline PI 179908 & Cll & 10.1 & 18.8 & 4.3 & $416-1-x x-5-25$ & Cll & 7.3 & $14.1 *$ & 4.3 \\
\hline PI 179910 & Cll & 5.1 & 24.3 & 4.3 & $416-2-x x-14$ & Cll & 8.7 & 20.8 & 5.4 \\
\hline PI 177325 & Cll & 13.5 & 19.9 & 3.0 & $416-2-x x-16$ & Cll & 6.5 & $15.4^{*}$ & 7.6 \\
\hline PI 177329 & Cll & 10.0 & 20.0 & 4.0 & $416-4-x x-3$ & Cll & 8.1 & 23.0 & 5.0 \\
\hline PI 179237 & Cll & 6.3 & $13.7 *$ & 3.6 & $416-4-x x-6$ & Cll & 8.2 & $17.6^{*}$ & 3.9 \\
\hline PI 185635 & Cll & 8.8 & 18.7 & 4.9 & $416-5-x x-11$ & Cll & 5.7 & 19.0 & 6.7 \\
\hline PI 186975 & Cll & 5.2 & 21.1 & 3.9 & $416-5-x x-20$ & Cll & 8.6 & 17.1 & 3.5 \\
\hline PI 189225 & Cll & 13.8 & $15.7 *$ & 3.6 & $416-4-x x-18-29$ & Cll & 7.9 & $14.2 *$ & 3.0 \\
\hline PI 189316 & Cll & 11.2 & 20.6 & 7.4 & 488-7-xx-18 & Cll & 5.2 & $15.9^{*}$ & 3.5 \\
\hline PI 189317 & Cll & 13.8 & 19.7 & 5.4 & $488-7-x x-22$ & Cll & 5.2 & 18.4 & 9.7 \\
\hline PI 189318 & $\mathrm{Cll}$ & 14.3 & $17.5^{*}$ & 5.9 & $488-7-x x-35$ & Cll & 4.0 & 21.3 & 4.9 \\
\hline PI 192937 & Cll & 9.0 & $12.5^{*}$ & 5.2 & Charleston Gray & Cll & 7.3 & $15.3^{*}$ & 2.4 \\
\hline
\end{tabular}

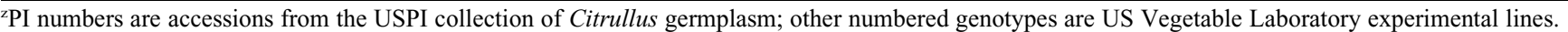

${ }^{\mathrm{y}} \mathrm{Cc}=$ Citrullus colocynthis; $\mathrm{Clc}=$ Citrullus lanatus $v$. citroides; $\mathrm{Cl}=$ Citrullus lanatus $v$. lanatus.

${ }^{\mathrm{x}}$ Means followed by asterisks are different from the control based on Fisher's protected least significant difference $(\mathrm{LSD})$ at $P \leq 0.05\left(\mathrm{LSD} \mathrm{P}_{0.05}=4.6\right)$.

${ }^{\mathrm{w}} \mathrm{SEM}=$ standard error of the mean.

nylon filters and pasteurized by heating to $70{ }^{\circ} \mathrm{C}$. Exudate solutions were diluted with distilled water to form concentrations of $0 \%$, $20 \%, 40 \%, 60 \%, 80 \%$, and $100 \%$ of the initial concentration, and $0.5-\mathrm{mL}$ aliquots of each concentration were tested using the millet bioassay procedure described previously, except no watermelon seeds were added to the dishes. The experiment was arranged in a completely random design with five replicates and the experiment was repeated. Data from the two repetitions of the experiment 
were combined and subjected to analysis of variance and means were separated using Fisher's protected LSD at $P \leq 0.05$. Four genotypes (Charleston Gray, 406-1-xx-7, PI 500354, and PI 582468) were chosen to demonstrate the differences in response curves. The response curves were generated using the quadratic regression equation $\left(y=y_{0}+\right.$ $\left.a x+b x^{2}\right)$.

Effect of Citrullus seed exudates on sporangia formation by Phytophthora capsici. Seven Citrullus genotypes included in this experiment (PI 167125, PI 432337, PI 482246, PI 500354, PI 532738, 406-1-xx-7, and Charleston Gray) were selected based on earlier observations and seed availability. PI 482246, which was not included in previous experiments, was included this experiment, because it appears to be tolerant to $P$. capsici. Seeds were soaked in distilled water $(30 \mathrm{~g}$ seeds $60 \mathrm{~mL}^{-1}$ ) on a wrist action shaker in the dark at $22{ }^{\circ} \mathrm{C}$. After $72 \mathrm{~h}$, the seeds were strained out and discarded, and the volume of the exudates was adjusted to $60 \mathrm{~mL}$. Exudates were filtered through sterile syringe filter (Corning, Corning, NY) disks $(0.20 \mu \mathrm{m})$ before use in bioassays. All P. capsici isolates used in these studies were kindly provided by A.P. Keinath, Clemson University, and R. French-Monar, University of Florida. In the first experiment, two isolates of $P$. capsici from South Carolina and two from Florida were used. Isolates were grown on parafilm wrapped V8 Juice agar plates containing the antibiotic rifampicin for 1 week using a technique described by Hausbeck and Lamour (2004). Mycelial agar plugs (6-mm diameter) of the individual isolates were placed in individual cells $(57 \times 108 \mathrm{~mm})$ on a 10-cell Boerner (Wheaton Scientific, Millville, NJ) microscope slide. One hundred fifty microliters of each seed exudate were directly pipetted on the agar plugs in each cell. There were three replications for each isolate and exudate combination. Sterile distilled water was used as a control. The Boerner microscope slides were placed in clear plastic boxes lined with two layers of moist paper towels to prevent drying of the exudates. The plastic boxes were placed on a laboratory bench $\left(25 \pm 1{ }^{\circ} \mathrm{C}\right)$ for $3 \mathrm{~d}$. Regular fluorescent lights in the laboratory were left on during daytime $(12 \mathrm{~h})$ for the $3 \mathrm{~d}$. Sporangia formation was monitored everyday. After $3 \mathrm{~d}, 50 \mu \mathrm{L}$ of sterile distilled water was added to each cell because of loss of volume of the exudates. Sporangia in each Boerner cell were dislodged from the mycelium and agar by rapidly pipetting back and forth for $10 \mathrm{~s}$. One microliter of sporangial suspension from each isolate and seed exudate combination was placed on a regular glass microscope slide and total number of sporangia counted. This experiment was repeated. Based on the results of the first two experiments, we selected three accessions (Charleston Gray, PI 432337, and PI 482334) for further studies on $14 P$. capsici isolates. Eight isolates from South Carolina and six from Florida were tested. There were two replications for each exudate and isolate combination. This experiment was conducted as described previously. The data were analyzed using log-transformed values for the spore counts; however, this did not alter the key conclusions, and hence the actual spore counts were used in final analysis and mean number of sporangia $\mu 1^{-1}$ are presented. Data were subjected to analysis of variance and means were separated by Fisher's protected LSD at $P \leq 0.05$.

\section{Results and Discussion}

The proso millet radicle growth bioassay described here was developed after preliminary experimentation to determine optimum conditions. The $70 \%$ ethanol rinse was used to reduce fungus growth associated with seeds of some genotypes, because in preliminary experiments, a dilute sodium hypochlorite bleach treatment that is often used to surface-sterilize seeds was found to reduce the inhibition by Charleston Gray seed exudates. The $70 \%$ ethanol rinse did not affect inhibition in comparison with untreated seeds. The initial germplasm assessment experiment indicated that watermelon genotypes vary in the inhibition of millet radicle growth caused by seed exudates (Table 1). Seed exudates of the Citrullus colocynthis accessions were not inhibitory in this bioassay, and only one accession of Citrullus lanatus v. citroides inhibited radicle growth. Exudates of most of the watermelon accessions included in this bioassay also did not inhibit proso millet radicle growth; however, radicles of seedlings grown in exudates of 53 accessions were shorter than the control. Radicles of seedlings grown in the exudates of two accessions were longer than the control. Increased growth by low concentrations of inhibitory compounds is common. Linear regression analysis indicated that the weight of the seeds added to the dishes and radicle lengths were not correlated. The frequency $(61 \%)$ of inhibitory genotypes in the U.S. Vegetable Laboratory lines was higher than in the PI accessions (37\%). There was considerable variation in this bioassay procedure as indicated by the relatively large standard errors for some means.

A more highly replicated experiment including selections from the preliminary germplasm evaluation indicated that detecting differences in the inhibitory potential of seed exudates of watermelon genotypes is possible. Radicle lengths of seedlings grown in seed exudates C. colocynthis (PI 432337) and C. lanatus $v$. citroides (PI 532738) accessions that were not inhibitory in the screening test were not different from the control in this study (Table 2). Radicle lengths of seedlings grown in exudates of watermelon accessions that were inhibitory in the preliminary experiment were all shorter than the control, but there were differences among the inhibitory accessions. This indicates that although a screening experiment with less replication may be useful to select genotypes with inhibitory seed exudates, highly replicated experiments are necessary to identify the most highly inhibitory selections. Two-way factorial analysis of the radicle growth data from this experiment indicated that the effect of experiment repetition and the interaction of genotype and repetition were not significant (data not included).

The seed biomass extracted per volume water was $\approx 4$ times higher in the procedure used to generate seed exudates for the concentration response experiments than in the whole seed bioassay. Thus, it is not surprising that seed exudates in this experiment were more inhibitory than exudates in the previous experiments (Table 3). Although PI 432337 and PI 532738 were not inhibitory in the whole seed bioassay (Tables 1 and 2), they were highly inhibitory in this experiment. The seed exudate concentration-response curves of four genotypes presented were different (Fig. 1). For instance, Charleston Gray exudate reduced radicle growth at all concentrations and maximum inhibition was $25 \%$ with the undiluted exudate; whereas PI 432337 exudate was not inhibitory at up to $60 \%$ concentration, but inhibition was $50 \%$ with undiluted exudate. The $20 \%$ concentration is approximately equivalent to the seed mass per volume water like in the whole seed bioassays (Tables 1 and 2), and at this

Table 2. Inhibition of proso millet seedling radicle growth by seed exudates of nine Citrullus genotypes in a petri dish bioassay.

\begin{tabular}{|c|c|c|c|}
\hline Genotype & Species $^{\mathrm{z}}$ & $\begin{array}{c}\text { Seed wt } \\
\left(\mathrm{g} \cdot 100 \text { seeds }^{-1}\right)\end{array}$ & $\begin{array}{c}\text { Radicle } \\
\text { length }^{\mathrm{y}} \\
(\mathrm{mm})\end{array}$ \\
\hline Control & - & - & $23.4 \mathrm{a}$ \\
\hline PI 432337 & $\mathrm{Cc}$ & 4.2 & $26.0 \mathrm{a}$ \\
\hline PI 532738 & $\mathrm{Clc}$ & 15.8 & $25.8 \mathrm{a}$ \\
\hline \multicolumn{4}{|l|}{ Charleston } \\
\hline Gray & $\mathrm{Cll}$ & 7.3 & $17.0 \mathrm{~cd}$ \\
\hline $389-5-x x-15$ & Cll & 3.1 & $17.3 \mathrm{c}$ \\
\hline $406-1-x x-7$ & $\mathrm{Cll}$ & 5.2 & $14.2 \mathrm{de}$ \\
\hline $413-5-x x-5$ & Cll & 3.6 & $12.9 \mathrm{e}$ \\
\hline $416-1-x x-5-25$ & Cll & 7.3 & $18.0 \mathrm{bc}$ \\
\hline $416-4-x x-6$ & Cll & 8.5 & $17.2 \mathrm{c}$ \\
\hline $416-5-x x-11$ & Cll & 8.1 & $20.2 \mathrm{~b}$ \\
\hline
\end{tabular}

${ }^{\mathrm{z}} \mathrm{Cc}=$ Citrullus colocynthis; $\mathrm{Clc}=$ Citrullus lanatus v. citroides $; \mathrm{Cl}=$ Citrullus lanatus $v$. lanatus.

yeans followed by the same letter are not different based on Fisher's protected least significant difference at $P \leq 0.05$.

Table 3. Effect of filtered, pasteurized exudates from seeds of eight Citrullus genotypes on proso millet radicle growth in bioassay.

\begin{tabular}{lcr}
\hline Genotype & Species $^{z}$ & $\begin{array}{r}\text { Radicle } \\
\text { length } \\
\text { (mm) }\end{array}$ \\
\hline Control & - & $22.4 \mathrm{a}$ \\
Charleston gray & Cll & $16.7 \mathrm{~b}$ \\
$406-1-x x-7$ & Cll & $11.2 \mathrm{c}$ \\
$413-5-x x-5$ & Cll & $15.8 \mathrm{~b}$ \\
PI-167125 & Cll & $12.1 \mathrm{c}$ \\
PI-432337 & Cc & $11.7 \mathrm{c}$ \\
PI-482246 & Cll & $10.3 \mathrm{c}$ \\
PI-500354 & Clc & $8.6 \mathrm{c}$ \\
PI-532738 & Clc & $11.0 \mathrm{c}$ \\
\hline
\end{tabular}

${ }^{\mathrm{z}} \mathrm{Cc}=$ Citrullus colocynthis; $\mathrm{Clc}=$ Citrullus lanatus v. citroides; $\mathrm{Cll}=$ Citrullus lanatus $v$. lanatus.

${ }^{\mathrm{y}}$ Means followed by the same letter are not different based on Fisher's protected least significant difference at $P \leq 0.05$. 
concentration, the relative inhibition of the four lines was similar to that observed in the whole seed bioassay. The marked difference in the characteristics of the concentrationresponse curves indicates that exudate constituents contributing to radicle growth inhibition probably vary among genotypes.
Most of the isolates used in the $P$. capsici bioassay experiments were obtained from cucurbits or peppers. In both experiments, inhibition of sporangia formation by seed exudates varied between genotypes (Tables 4 and 5). For data averaged over four isolates, seed exudates of a C. colocynthis accession,

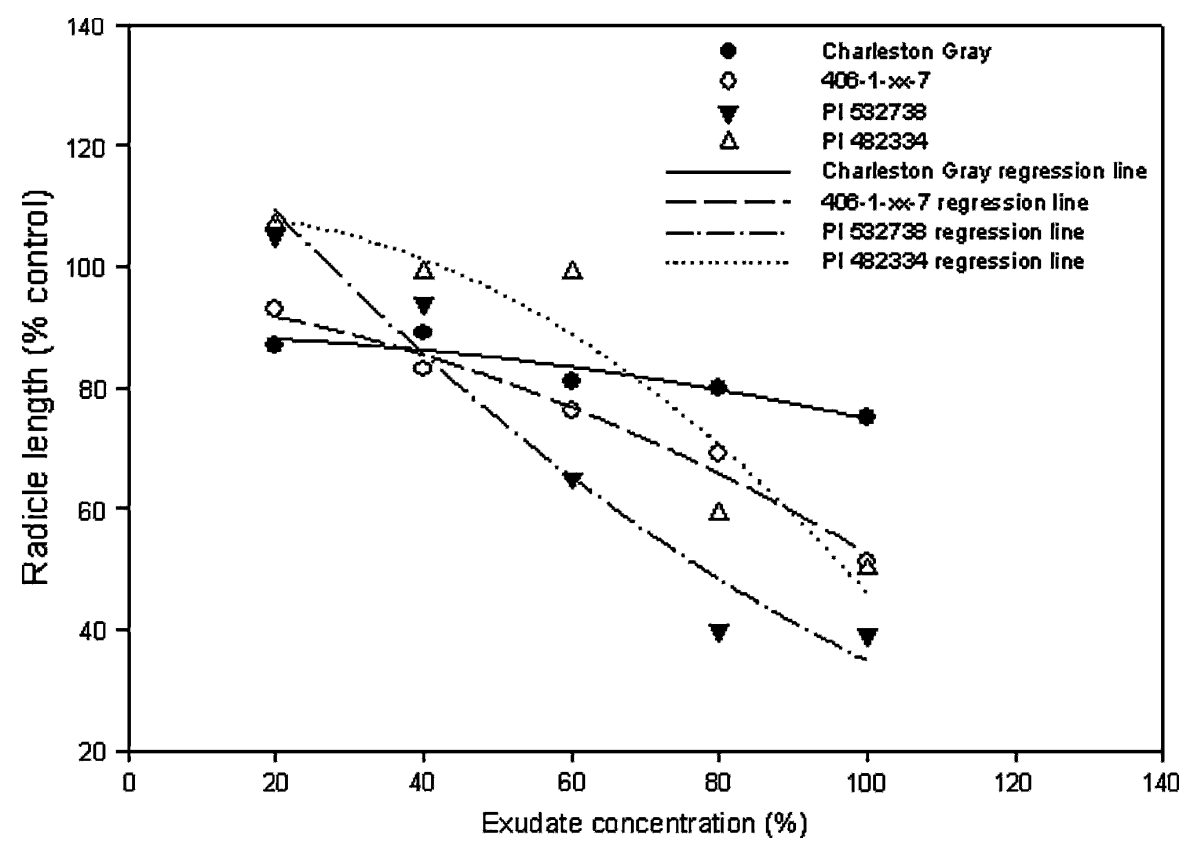

Fig. 1. Concentration response curves for seed exudates from four Citrullus genotypes. Curves were generated using the quadratic regression equation $\left(y=y_{0}+a x+b x^{2}\right) . \mathrm{R}^{2} \mathrm{~s}$ were $0.88,0.95,0.90$, and 0.81 and $P$ s were $0.11,0.022,0.048$, and 0.093 for Charleston Gray, 406-1-xx-7, PI 500354, and PI 482334 , respectively.

Table 4. Effect of seed exudates from nine Citrullus genotypes on sporangial formation by Phytophthora capsici. ${ }^{2}$

\begin{tabular}{|c|c|c|c|}
\hline \multirow[b]{2}{*}{ Watermelon genotype } & \multirow[b]{2}{*}{ Species $^{y}$} & \multicolumn{2}{|c|}{ Number of sporangia $\cdot \mu \mathrm{L}^{-1 x}$} \\
\hline & & Expt. I & Expt. II \\
\hline Water control & & $64 \mathrm{a}$ & $58 \mathrm{a}$ \\
\hline PI 482246 & $\mathrm{Cll}$ & $67 \mathrm{a}$ & $60 \mathrm{a}$ \\
\hline PI 500354 & $\mathrm{Clc}$ & $59 \mathrm{a}$ & $56 \mathrm{ab}$ \\
\hline PI 532738 & $\mathrm{Clc}$ & $54 \mathrm{ab}$ & $30 \mathrm{~cd}$ \\
\hline Charleston Gray & Cl151 ab & $37 \mathrm{abc}$ & \\
\hline $406-1-x x-7$ & C1150 ab & $45 \mathrm{abc}$ & \\
\hline PI 167125 & Cl150 ab & $52 \mathrm{abc}$ & \\
\hline PI 432337 & $\mathrm{Cc} 21 \mathrm{bc}$ & $9 \mathrm{de}$ & \\
\hline PI 482334 & $\mathrm{Clc} 9 \mathrm{c}$ & $3 \mathrm{e}$ & \\
\hline \multicolumn{4}{|l|}{ Analysis of variance } \\
\hline \multicolumn{4}{|l|}{ Expt. I } \\
\hline Source & Degrees of freedom & Mean square & $P$ \\
\hline Rep & 2 & 332 & 0.5880 \\
\hline Watermelon genotype & 9 & 4158 & 0.0001 \\
\hline P. capsici isolate & 3 & 31931 & 0.0001 \\
\hline Genotype $\times$ isolate & 27 & 1697 & 0.0003 \\
\hline \multicolumn{4}{|l|}{ Expt. II } \\
\hline Rep & 2 & 194 & 0.7956 \\
\hline Watermelon genotype & 9 & 4754 & 0.0001 \\
\hline P. capsici isolate & 3 & 16462 & 0.0001 \\
\hline Genotype $\times$ isolate & 27 & 1693 & 0.0101 \\
\hline
\end{tabular}

${ }^{\mathrm{Z}}$ Data are averaged over four $P$. capsici isolates.

${ }^{\mathrm{y}} \mathrm{Cc}=$ Citrullus colocynthis $; \mathrm{Clc}=$ Citrullus lanatus $v$. citroides $; \mathrm{Cll}=$ Citrullus lanatus $v$. lanatus.

${ }^{x}$ Means followed by same letter within columns are not significantly different based on Fisher's protected least significant difference at $P \leq 0.05$.

PI 432337, and a C. lanatus $v$. citroides accession, PI 482334, significantly inhibited sporangial formation compared with sterile, distilled water control (Table 4). The variation in the effect of seed exudates on different isolates is demonstrated by the highly significant isolate effect and the genotype-by-isolate interaction. Not all isolates were inhibited by PI 482334 and PI 432337 exudates (data not presented). In the second experiment, the seed exudates of all three genotypes inhibited sporangia formation when averaged over 14 isolates (Table 5). The isolate effect was also highly significant in this experiment, which indicates that isolates varied in response to the exudates, but the genotype $\times$ isolate interaction was not significant. No seed exudate completely inhibited sporangial formation, and at least a few sporangia were formed in all combinations. None of the seed exudates inhibited growth of the seedborne, bacterial watermelon fruit blotch pathogen, Acidovorax avenae subsp. citrulli (data not presented). We consider these results to be preliminary evidence that watermelon seed constituents may play a role in the interaction of pathogens with germinating Citrullus seeds. Further study is required to determine if the inhibition of sporangia formation observed in this bioassay occurs under natural conditions.

In these experiments, inhibition by watermelon seed exudates in the millet and $P$. capsici bioassays varied considerably among genotypes. The differences in the characteristics among genotypes in concentration response curves for the proso millet radicle growth bioassay (Fig. 1) and the differences among genotypes in relative inhibition in the millet and $P$. capsici bioassays (Tables 2-5) indicate that the inhibitory components of the seed exudates may vary among genotypes used in these studies. Kushima et al. (1998) reported that most of the inhibition of seedling growth was attributable to vanillic acid that was present at high concentrations in watermelon seed exudate. They did not specify the watermelon genotype that was used in their studies. It is unlikely that their genotype was included in our experiments. Preliminary chromatographic examination of phenolic constituents occurring in the exudates and extracts of seeds of 10 of the Citrullus genotypes included in these studies indicated that vanillic acid or its glycoside, vanillin, was not present at the high levels that they reported (Maurice E. Snook, personal communication).

It is doubtful that allelopathic potential associated with watermelon seed exudates could contribute to weed management under U.S. cultural practices, because the seeding rate is low and watermelon is often transplanted. However, if watermelon seedlings are also allelopathic, then the trait may be useful to improve competitiveness against weeds. Lockerman and Putnam (1979) found that allelopathic cucumber genotypes were more competitive than nonallelopathic genotypes in a field weed interference experiment. 
Table 5. Effect of seed exudates from three Citrullus genotypes on sporangial formation Phytophthora capsici. $^{\mathrm{z}}$

\begin{tabular}{lccc}
\hline Seed exudate & Sporangia number $\mu \mathrm{l}^{-1} \mathrm{y}$ & & \\
\hline Control & $117 \mathrm{a}$ & \\
Charleston Gray & $68 \mathrm{~b}$ & \\
PI 432337 & $39 \mathrm{c}$ & \\
PI 482334 & $25 \mathrm{c}$ & & \\
Analysis of variance & & & \\
$\quad$ Source & Degrees of freedom & Mean square & $P$ \\
$\quad$ Rep & 1 & 20089 & 0.0001 \\
$\quad$ Watermelon genotype & 3 & 47441 & 0.0001 \\
$\quad P$. capsici isolate & 13 & 8389 & 0.0001 \\
$\quad$ Genotype $\times$ isolate & 39 & 1339 & 0.2870 \\
\hline
\end{tabular}

${ }^{\mathrm{z}}$ Data are averaged over 14 isolates.

${ }^{y}$ Means followed by same letter within columns are not significantly different based on Fisher's protected least significant difference at $P \leq 0.05$.

The biological activity of Citrullus seed exudates and the differences between genotypes in seed exudate activity warrant continued investigation of the trait.

\section{Literature Cited}

Hausbeck, M.K. and K.H. Lamour. 2004. Phytophthora capsici on vegetable crops: Research progress and management challenges. Plant Dis. 88:1292-1303.

Higashinakasu, K., K. Yamada, H. Shigemori, and K. Hasegawa. 2004. Effects of seed exudates of several plant species during germination stage. Weed. Biol. Man. 4:171-175.

Jester, W.R., M.L. Adams, and G.J. Holmes. 2006. Evaluation of cultural practices and fungicides for control of Phytophthora blight of watermelon. F\&N Tests 61:V111.
Kushima, M., H. Kakuta, S. Kosemura, S. Yamamura, K. Yamada, K. Yokotani-Tomita, and K. Hosegawa. 1998. An allelopathic substance isolated from germinating watermelon seeds. Plant Growth Reg. 25:1-4.

Lockerman, R.H. and A.R. Putnam. 1979. Evaluation of allelopathic cucumbers (Cucumis sativus) as an aid to weed control. Weed Sci. 27: 54-57.

Lockerman, R.H. and A.R. Putnam. 1981. Mechanisms for differential interference among cucumber (Cucumis sativus L.) accessions. Bot. Gaz. 142:427-430.

Nelson, E.B. 1990. Exudate molecules initiating fungal response to seeds and roots. Plant Soil 129:61-73.

Nelson, E.B. 2004. Microbial dynamics and interactions in the spermosphere. Ann. Rev. Phytopathol. 42:271-309.
Ohno, S., K. Tomita-Yokotani, S. Kosemura, M. Node, T. Suzuki, and M. Amano. 2001. A species selective allelopathic substance from germinating sunflower (Helianthus annuus L.) seeds. Phytochemistry 56:577-581.

Otlewski, J., H. Whatley, A. Polanoski, and T. Wilusz. 1987. Amino acid sequences of trypsin inhibitors from watermelon (Citrullus vulgaris) and red bryony (Bryonia dioica) seeds. Biol. Chem. 368:1505-1507.

Putnam, A.R. and W.B. Duke. 1974. Biological suppression of weeds: Evidence for allelopathy in accession of cucumber. Science 185:370 372.

Rice, E.L. 1984. Alleopathy. 2nd ed. Academic Press, Inc., Orlando, FL.

Rose, T.L., A. da Silva Conceicas, J. Xavier-Filho, L.A. Okorokov, K.V.S. Fernandes, F. Marty, D. Marty-Mazars, A.O. Carvalho, and V.M Gomes. 2006. Defense proteins form Vigna unguiculata seed exudates: Characterization and inhibitory activity against Fusarium oxysporum. Plant Soil 286:181-191.

Wiant, J.S. 1940. A rot of Winter Queen watermelon caused by Phytophthora capsici. J. Agr. Res. 60:73-88.

Yamada, T., T. Anai, and K. Hasegawa. 1995. Lepidimoide, an allelopathic substance in the exudates from germinated seeds. Phytochemistry 39:1031-1032.

Yu, J.Q. 2001. Autotoxic potential of cucurbit crops; phenomenon, chemicals, mechanisms and means to overcome. J. Crop Prod. 4:335-348.

Yu, J.Q. and Y. Matsui. 1994. Phytotoxic substances in the root exudates of Cucumis sativus L. J. Chem. Ecol. 20:21-31.

Yu, J.Q., S.Y. Shou, Y.R. Qian, and W.H. Hu. 2000. Autotoxic potential in cucurbit crops. Plant Soil 223:147-151. 